\title{
EL LENGUAJE DE LA LEY HUMANA EN EL PENSAMIENTO DE FRANCISCO SUÁREZ"
}

\author{
FERNANDO CENTENERA SÁNCHEZ-SECO \\ Universidad de Alcalá
}

\begin{abstract}
RESUMEN. En este trabajo se aborda el tema del lenguaje de la ley humana en el pensamiento de Francisco Suárez. El desarrollo se lleva a cabo teniendo en cuenta principalmente el Tratado de las leyes y de Dios legislador y comprende los siguientes aspectos: el carácter preceptivo del lenguaje legislativo, la forma escrita y oral, el nivel léxico-semántico y la claridad lingüística desde las perspectivas de la conveniencia, la esencia de la ley y la justicia. Las cuestiones tratadas por Suárez a propósito de estos aspectos han seguido siendo objeto de atención en épocas posteriores y en nuestros días. Hoy la lectura de algunas de ellas infunde la idea de que siguen vigentes. Por todo ello, junto a la exposición de contenidos, que pretende describir y ofrecer pautas para entender las ideas del jesuita, se presentan otros análisis de carácter comparativo y reflexivo; aunque sin perder de vista que nos centramos en un autor que escribió en la Edad Moderna.
\end{abstract}

PALABRAS CLAVE: Suárez; ley; lenguaje; prescripción; escritura; oralidad; léxico; semántica; claridad.

\section{The language of human law in the thought of Francisco Suárez.}

ABSTRACT. The subject of this article is the language of human law in the thought of Francisco Suárez. Its chief focus is on the Treatise on Laws and on God the Lawgiver and its views on the prescriptive nature of legislative language, written and spoken language, the lexical-semantic level, and linguistic clarity from the viewpoints of convenience, the essence of the law and justice. The issues Suárez deals with in relation to these points have continued to attract attention up to the present day, and a reading of the Treatise confirms the impression that some of them are still valid. Accordingly, as well as setting out, describing and offering a guide to understanding Suárez's ideas, the article offers a comparative and contemplative analysis of them, without forgetting that their author belonged to the early modern period.

KEY WORDS: Suárez; law; language; prescription; writing; orality; lexicon; semantics; clarity.

\section{INTRODUCCIÓN}

La obra jurídica de Francisco Suárez ha venido llamando la atención de numerosos estudios en la época contemporánea, aunque a menudo se ha abordado con carácter general ${ }^{1}$. Sin embargo, no son tan prolíficos los trabajos

Este artículo se enmarca dentro del Proyecto I+D+I «Pensamiento y tradición jesuita y su influencia en la Modernidad desde las perspectivas de la Historia, la Traductología y la Filosofía Jurídica, Moral y Política»(PEMOSJ), financiado por el Ministerio de Economía y Competitividad del Gobierno de España y el Fondo Europeo de Desarrollo Regional (MINECO/FEDER) (referencia FFI2015-64451-R), y cuyo investigador principal es el Prof. Dr. Juan Antonio Senent de Frutos.

1 La circunstancia es casi obligada en referencias de carácter general como las siguientes: Truyol y Serra, A., Historia de la Filosofía del Derecho y del Estado, vol. 2. Del Renacimiento a Kant, Alianza Editorial, 2. ${ }^{a}$ edición, Madrid, 1982, pp. 137-142; FAssò, G., 
dedicados a temas concretos, como puede ser, por ejemplo la teoría de la ley². Esta apreciación cobra a nuestro juicio especial relevancia si nos referimos a los aspectos formales de aquella; si bien debe apuntarse que la preocupación por esta parcela de análisis no ha estado totalmente ausente ${ }^{3}$. Esta circunstancia nos ha animado a desarrollar este trabajo en el ámbito recientemente expuesto; concretamente centramos la atención en el lenguaje de la ley humana en el pensamiento de Suárez. Al menos hasta donde llegamos a conocer, apenas hay estudios que se dediquen exclusivamente a este tema, si bien es cierto que en las décadas recientes encontramos interesantes referencias, que reservan algún espacio para analizar aspectos concretos de la cuestión que nos interesa. En este estudio tendremos en cuenta estos trabajos.

En el desarrollo que presentamos hemos centrado la atención, casi de forma exclusiva, en el Tratado de las leyes y de Dios legislador. En él no encontramos un tratado dedicado al lenguaje de la ley humana, ni tampoco un estudio sistemático sobre aquel. Sin embargo, el jesuita se refiere puntualmente a numerosos aspectos, a propósito del tratamiento de diferentes cuestiones, que podrían enmarcarse en dicha temática. Nuestra intención es estudiar los contenidos que consideramos más representativos; concretamente, abordaremos los siguientes: el carácter preceptivo del lenguaje legislativo, la forma escrita y hablada, el nivel léxico-semántico y la claridad del lenguaje considerada desde los puntos de vista de la conveniencia, la esencia de la ley y la justicia.

Por una parte, el desarrollo que presentamos tiene carácter descriptivo. Desde esta perspectiva pretendemos dar a conocer las ideas del jesuita y proporcionar algunas pautas para entenderlas mejor. Por otra parte, en las siguientes páginas podrán verse también aportes comparativos y reflexivos. Suárez analiza cuestiones que han suscitado atención en épocas posteriores y en nuestros días; incluso en ocasiones su lectura infunde la idea de que varios de esos contenidos siguen teniendo vigencia en la actualidad. Estas circunstancias invitan casi de forma ineludible a plantear desarrollos en la línea expuesta en segundo lugar. En ello, no obstante, hemos tratado de no olvidar que Suárez

Historia de la Filosofía del Derecho, vol. 2. La Edad Moderna, Ediciones Pirámide, Madrid, 1979, pp. 64-66.

2 Según Amezúa, apenas existen estudios contemporáneos que se hayan preocupado por la teoría de la ley en Suárez, con algunas salvedades. Amezúa Amezúa, L. C., «Efectos de la Ley y Permisos: el legado de un clásico del Siglo de Oro (Textos para el IV Centenario de Francisco Suárez)», en: I Congreso de Filosofía del Derecho para el Mundo Latino, 2628 de mayo de 2016, p. 1. Consultado en http://iusfilosofiamundolatino.ua.es/download/ Luis\%20Carlos\%20Amezu\%CC\%81a\%20-\%20Espan\%CC\%83a.pdf. Fecha de consulta: 23/10/2016.

3 Quizá sea significativo citar la referencia de Recasens Siches, L., La Filosofía del Derecho de Francisco Suárez. Con un estudio previo sobre sus antecedentes en la patrística y en la escolástica, Librería General de Victoriano Suárez, Madrid, 1927, pp. 153-155; y principalmente la de Macía Manso, R., Juridicidad y moralidad en Suárez, Publicaciones del Instituto de Estudios Jurídicos, Oviedo, 1967, pp. 73 y ss. y 133 y ss. 
escribió en una época que queda lejos de la actual y que por ello, la vigencia de sus ideas a la que antes hacíamos referencia, al menos si aquellas se analizan en su contexto, probablemente deberá ser matizada. Concluimos esta introducción señalando que en la parte final de este trabajo hemos considerado algunas ideas desarrolladas en estudios sobre la claridad normativa en el pensamiento de Lon L. Fuller ${ }^{4}$, pues entendemos que puede resultar interesante constatar posibles reflejos del pensamiento del jesuita en el contexto citado.

\section{LENGUAJE PRECEPTIVO}

Para Suárez la ley es «un precepto común, justo y estable, suficientemente promulgado» ${ }^{5}$. Como puede observarse, el comienzo de esta definición hace referencia al carácter de ordenación que tiene la ley que, a fin de cuentas, se presenta como una señal de la voluntad de quien tiene la soberanía y que «se da a los súbditos ${ }^{6}$. Si ello es así, cabría entender que en rigor no puede decirse que estemos ante una ley cuando hablamos de un consejo o una petición. En estos casos no nos encontramos ante una ordenación de superior a inferiores, pues tienen lugar entre iguales o de inferior a superior ${ }^{7}$.

La concepción imperativa de la ley que enmarca los argumentos anteriores puede percibirse mucho antes de que Suárez escribiera, en los años siguientes a su obra ${ }^{8}$ y también en nuestro tiempo. En este último contexto las ideas expuestas siguen estando presentes en numerosos estudios. Así, con ocasión del tratamiento de la función del lenguaje normativo se constata que aquella es expresión de la voluntad de quien emite la ley, que se encuentra en una posición superior con respecto a la audiencia de aquella ${ }^{9}$. Además, puede resultar interesante señalar que tal planteamiento se enmarca dentro del rótulo «función directiva o prescriptiva», y a propósito de ello debe precisarse

4 Así, en Centenera Sánchez-Seco, F., «Buscando el valor de la claridad de las normas: Algunas reflexiones desde el pensamiento de Lon L. Fuller», en: Bajo Palabra. Revista de Filosofía, 10, 2015, pp. 61-70; Centenera SÁnchez-Seco, F., «La claridad legislativa en el pensamiento de Lon L. Fuller: Un análisis desde la teoría de la legislación», en: Anales de Derecho, 1, 2015, pp. 1-27.

5 Suárez, F., Tratado de las leyes y de Dios legislador, vol. I, Instituto de Estudios Políticos, Madrid, 1967, p. 65 (I, XII, 5).

6 SuÁrez, F., Tratado de las leyes y de Dios legislador, vol. II, Instituto de Estudios Políticos, Madrid, 1967, p. 256 (III, XV, 1).

7 SuÁrez, F., Tratado de las leyes..., vol. I, p. 64 (I, XII, 4).

8 Sobre ello puede consultarse, por ejemplo De Páramo, J. R., H. L. A. Hart y la teoría analítica del derecho, Centro de Estudios Constitucionales, Madrid, 1984, pp. 119, 120, $121,131$.

9 Ansuátegui, F. J., «El derecho como norma», en: Peces-Barba, G., Fernández, E., De Asís, R., Curso de Teoría del Derecho, Marcial Pons, segunda edición, Madrid, 2000, p. 149. 
que esta categoría abarca una panoplia de acciones lingüísticas que van más allá del ámbito normativo. Así, dentro del uso directivo, con el que se pretende dirigir el comportamiento, encontramos las súplicas, ruegos, sugerencias, recomendaciones, consejos, peticiones, órdenes, etc. Sin embargo, en este contexto únicamente tienen relación con las normas las directivas que tengan mayor fuerza, es decir, las prescripciones ${ }^{10}$. Por otra parte, quien emite el consejo o la petición supedita su cumplimiento a la persona destinataria ${ }^{11}$. No se trata, por tanto, en estos casos de una relación entre superior e inferior. Como decíamos, estos planteamientos recuerdan a la postura de Suárez expuesta. No obstante, cabría puntualizar que un análisis detenido, centrado por ejemplo en el ámbito terminológico, descubre diferencias. El detalle del uso de la palabra «súbditos» en la obra del jesuita es representativo de lo que decimos $^{12}$.

Para Suárez el planteamiento del que hemos partido ha de encontrar reflejo en el lenguaje, mediante el uso de palabras preceptivas. De este modo, considera que el modo de expresión puede ser imperativo o indicativo. En el primer caso hablamos de expresiones del tipo "haced», «absteneos», etc. Parece que en la época del autor se cuestionó el hecho de que estas fórmulas fueran correctas para establecer una ley obligatoria. Sin embargo, el jesuita las da por buenas, pues los preceptos de quienes son superiores se dan según el modo apuntado, y por lo general se entiende que aquellas son suficientes, puesto que indican mandato ${ }^{13}$. En lo que respecta a la expresión en forma indicativa, Suárez considera preceptos afirmativos, a propósito de los cuales se utilizan las palabras «ordeno» o «mando», que indican «voluntad de obligar»; y preceptos negativos, que se expresan con palabras como "prohíbo»" ${ }^{14}$. El autor contempla además la posibilidad de usar otras fórmulas que sean equivalentes, como por ejemplo «Todos estén obligados, a ninguno le sea lícito» ${ }^{15}$. Además de todo ello, analiza el uso de algunas palabras concretas, como, por ejemplo,

10 Nino, C., Introducción al análisis del Derecho, Ariel, 11 a edición, Barcelona, 2003, pp. 64-66. Sobre la cuestión también Von Wright, G. H., Norma y Acción. Una investigación lógica, Editorial Tecnos, reimpresión, Madrid, 1979, p. 88.

11 Nino, C., o. c., p. 66.

12 En un análisis contextual cabría constatar más diferencias, al menos si se asume la postura de que la obligación no debe ser necesariamente justa —característica que sí se aprecia en Suárez-, sino susceptible de ser calificada en términos de justa o injusta. Sobre esto último Ansuátegui, F. J., o. c., p. 149. La cuestión entendemos que remite al debate entre iusnaturalismo y positivismo, y que por tanto puede ejemplificarse con el enfrentamiento entre el planteamiento suareciano, y aquel que tiempo después desarrollaría Hobbes, que recoge también el carácter imperativista de la ley, pero que plantea una definición de ley neutral desde el punto de vista ético (HobBes, T., Leviatán o la materia, forma y poder de un Estado eclesiástico y civil, Alianza Editorial, primera reimpresión, Madrid, 2001, p. 232, donde leemos «no pudiéndose decir que algo es injusto si no es contrario a alguna ley»). Sobre esta idea De Páramo, J. R., o. c., p. 120.

13 SuÁrez, F., Tratado de las leyes..., vol. II, pp. 258, 259 (III, XV, 7, 8).

14 Ibid., p. 258 (III, XV, 8).

15 Ibid., p. 258 (III, XV, 8). 
el verbo «conviene». A su entender, si bien según Azpilcueta y Medina es suficiente para transmitir el mandato de la ley, no parece que deba entenderse de tal forma, pues la palabra en cuestión indica juicio y no mandato; siendo ello, como señala Castro, signo de honestidad y no de necesidad ${ }^{16}$. Desde una interpretación contextual de los aspectos recientemente expuestos, parece que deberían enmarcarse en el ámbito de la formalidad de la promulgación de la ley. Una interpretación en este sentido invita a considerar una reflexión en clave actual. Aunque no con la estructura que puede apreciarse en la legislación de la época de Suárez, en nuestro tiempo la Corona sigue utilizando la palabra «mando» en la cláusula de ejecutoriedad de la ley ${ }^{17}$. Quizá deba verse aquí la impronta de la tradición histórica, pero como se ha dicho, de ser así la fórmula debería reconsiderarse, pues en el contexto actual la obligatoriedad de la ley procede del parlamento ${ }^{18}$.

No obstante, a nuestro modo de ver el desarrollo del jesuita podría tener una segunda lectura, aunque no necesariamente excluyente de la recientemente expuesta. Algunos detalles de su texto dan motivos para entender que -quizá, además de tener en cuenta lo anterior-, Suárez pudiera estar pensando en la parte de la ley que establece el mandato o prohibición de acciones concretas; es decir, lo que hoy conocemos como parte dispositiva. A propósito de ello, resulta muy interesante destacar los siguientes modelos que propone a modo de ejemplo: «todos paguen», «absteneos», «confiésese cuantos [sic.] antes» ${ }^{19}$. Este planteamiento quizá pueda extrañar en nuestro tiempo, pues los preceptos de las normas no necesariamente se presentan conforme a dicha estructura. Pensamos, no obstante, que el discurso del jesuita encuentra correspondencia con numerosos textos legislativos de su época que hemos tenido oportunidad de consultar, en los que se ordenaban, prohibían o permitían acciones determinadas. Ejemplos de ello se pueden localizar en la Prematica, y nveva orden, cerca de los vestidos, y trages, assi de hombres, como de mujeres, y de otras cosas, que se mandan guardar ${ }^{20}$; on

16 Ibíd., p. 259 (III, XV, 10).

17 La orden de ejecutoriedad, es decir, el mandato que la Corona trasmite a la ciudadanía, tiene la fórmula "por tanto, mando a todos los españoles...». Viver PI-SunYer, C., "Sanción, promulgación y orden de publicación», en: Gretel, Curso de técnica legislativa, Centro de Estudios Constitucionales, Madrid, 1989, pp. 106, 108.

18 Sobre ello Viver Pi-Sunyer, C., o. c., p. 108. En el caso del jesuita entendemos que se trata de un planteamiento bastante consistente. Para el granadino las palabras han de transmitir de forma suficiente «la intención del soberano». SuÁrez, F., Tratado de las leyes..., vol. II, p. 258 (III, XV, 7). El autor piensa probablemente en la monarquía de manera principal, pero extiende su discurso a otras formas de gobierno, como el conformado por muchas personas. Sobre este último SuÁrez, F., Tratado de las leyes..., vol. II, p. 257 (III, XV, 4); SuÁrez, F., Tratado de las leyes..., vol. I, p. 46 (I, VIII, 9).

19 SuÁrez, F., Tratado de las leyes..., vol. II, p. 259 (III, XV, 8).

20 Prematica, y nveva orden, cerca de los vestidos, y trages, assi de hombres, como de mujeres, $y$ de otras cosas, que se mandan guardar, Iuan de la Cuesta, Madrid, 1611. Consultado en http://alfama.sim.ucm.es/dioscorides/consulta_libro.asp?ref=b25218347\&idioma=0. Fecha de consulta: 10/11/2016. 
la Prematica de tratamientos, y cortesias, y se acrecientan las penas contra los transgresores de lo en ella contenido ${ }^{21}$.

Para finalizar este apartado, quisiéramos señalar que el contenido desarrollado podría analizarse también desde la perspectiva del lenguaje deóntico, que en cierta medida puede percibirse en algunos detalles ya expuestos, pero que el granadino aborda de forma más generosa en otras partes de su obra ${ }^{22}$. Según él, para que exista ley esta debe imponer una obligación, es decir, la necesidad de hacer o no hacer algo ${ }^{23}$. Poco después analiza si la obligación es el único efecto de la ley ${ }^{24}$, y considera equivalencias del tipo «mandar y prohibir son formalmente lo mismo; sólo se distinguen materialmente» ${ }^{25}$. Tal planteamiento encuentra reflejo en la lógica deóntica contemporánea, así $\mathrm{OX} \leftrightarrow \mathrm{Ph}-\mathrm{X}^{26}$; por ejemplo, es obligatorio pagar el impuesto equivale a está prohibido no pagar el impuesto. En relación a todo ello, Suárez entiende que precepto y prohibición imponen una obligación de diferente manera ${ }^{27}$. Por otra parte, el autor se refiere a los permisos, que pueden ser efecto de ley, refiriéndose a una acción buena o mala ${ }^{28}$; o no efecto del imperio, sino de su ausencia. En este último caso basta la no prohibición de la acción ${ }^{29}$. El jesuita también considera que una ley permisiva conlleva una obligación para alguien de alguna forma ${ }^{30}$. Estos aspectos encuentran reflejo en obras contemporáneas como la de Von Wright ${ }^{31}$ quien, no obstante, reconsideró su postura en relación a la segunda categoría

21 Prematica de tratamientos, y cortesias, y se acrecientan las penas contra los transgresores de lo en ella contenido, Iuan de la Cuesta, Madrid, 1611. Consultado en http:// alfama.sim.ucm.es/dioscorides/consulta_libro.asp?ref=b2521844x\&idioma=0. Fecha de consulta: 10/11/2016.

22 En ocasiones se ha considerado a Bentham precursor de la lógica deóntica (sobre ello De Páramo, J. R., o. c., p. 132), pero en vista de lo que decimos en el texto probablemente habría que reconocer antecedentes anteriores.

23 SuÁrez, F., Tratado de las leyes..., vol. I, p. 68 (I, XIV, 4).

24 Pueden encontrarse estudios más generosos sobre la cuestión que tratamos en Amezúa Amezúa, L. C., o. c., pp. 2 y ss.; Lecón, M., Acción, praxis y ley. Estudio metafísico y psicológico de la acción legislativa en Francisco Suárez, EUNSA, Navarra, 2014, pp. 122 y ss. Quizá las principales aportaciones de nuestro desarrollo en este punto sean la constatación de determinados reflejos de las ideas de SuÁREz en la literatura jurídica contemporánea, y la objeción que presentamos en relación a los permisos.

25 SuÁrez, F., Tratado de las leyes..., vol. I, p. 71 (I, XV, 1).

26 En esta representación seguimos la exposición de Ansuátegui, F. J., o. c., p. 154. Según esta fuente: $\mathrm{P}=$ Permitido, $\mathrm{O}=$ Obligatorio, $\mathrm{Ph}=$ Prohibido, -=negación, $\leftrightarrow$ =equivalencia, $\mathrm{X}=$ acción determinada.

27 SuÁrez, F., Tratado de las leyes..., vol. I, p. 71 (I, XV, 4).

28 Ibid., p. 73 (I, XV, 9).

29 Ibíd., p. 71 (I, XV, 1, 8).

$30 \quad$ Ibid., p. 74 (I, XV, 12).

31 En ella aparecen los permisos como «simple ausencia o no existencia de las prohibiciones», y como una «especie particular de prohibiciones; a saber, prohibiciones de interferir la libertad de un agente en un determinado respecto». Von Wright, G. H., o. c., pp. 100, 101. 
de permisos citada $^{32}$, objetable en nuestro tiempo ${ }^{33}$, y entendemos que también en el de Suárez ${ }^{34}$.

\section{FORMA ESCRITA Y ORAL}

Otra de las cuestiones relacionadas con el lenguaje legislativo que encontramos en la obra de Suárez es su forma de expresión, escrita y hablada. Concretamente, el jesuita se ocupa de ello a propósito de la pregunta de «¿qué forma externa o sensible se ha de observar al dar una ley humana?». Su respuesta es que aquella ha de ser una señal sensible que se ajuste al conocimiento de las personas $^{35}$. En este sentido, puede considerarse que la forma escrita es la mejor para dar una ley, pues contribuye a su estabilidad y es necesaria para examinar detenidamente las palabras de la ley ${ }^{36}$. Esta idea no es genuina del autor, se puede localizar mucho tiempo antes ${ }^{37}$. Se trata, sin duda de un discurso muy acertado, si bien un análisis histórico nos da razones para pensar que

32 Entendemos que concretada por parte de Suárez en el siguiente sentido: un acto está permitido mientras no esté prohibido. SuÁREz, F., Tratado de las leyes..., vol. I, p. 73 (I, XV, 8).

33 Una circunstancia no regulada puede resolverse conforme a principios o por analogía, resultando de ello la prohibición. La cuestión se analiza de forma pormenorizada, junto con otras razones, en ItURRALde SESma, V., «Consideración crítica del principio de permisión según el cual "lo no prohibido está permitido" », en: Anuario de Filosofía del Derecho, 15, 1998, pp. 199 y ss. La postura de SuÁrEz, no obstante, entendemos que podría entenderse en base a varias consideraciones. Una de las más representativas es la que tiene que ver con su excesiva fijación en la ley, en detrimento de un tratamiento más generoso del ordenamiento jurídico. Es cierto que pueden considerarse aportaciones en este último sentido, como así se constata en Pérez Luño, A.-E., «Francisco Suárez y la Filosofía del Derecho actual», en: I Congreso de Filosofía del Derecho para el Mundo Latino, 26-28 de mayo de 2016, pp. 22 y ss. Consultado en http://iusfilosofiamundolatino.ua.es/download/Ponencia\%20Pe $\%$ CC $\% 81 \mathrm{rez} \% 20 \mathrm{Lun} \% \mathrm{CC} \%$ 83o.pdf. Fecha de consulta: 23/10/2016. Sin embargo, a nuestro modo de ver se trata de aspectos generales. Por otra parte, en su estudio sobre la ley el jesuita sí que considera determinadas cuestiones, como por ejemplo, la irretroactividad —SuÁrEz, F., Tratado de las leyes..., vol. II, p. 254 (III, XIV, 8) —, que sí abonan el argumento de que se pueda aplicar la idea que venimos considerando, aunque únicamente en materia sancionadora (sobre ello, en términos generales, Iturralde Sesma, V., o. c., p. 212).

34 Así pensamos que ha de entenderse si tenemos en cuenta que, como diremos, en la época del jesuita existían principios (aunque no como los entendemos en nuestros días) y argumentaciones suficientemente desarrolladas, como la analogía. Sobre esto último GarcíaGallo, A., Manual de Historia del Derecho Español, vol. I, [s. ed.], Madrid, 1982, p. 304.

35 Sú́rez, F., Tratado de las leyes..., vol. II, p. 256 (III, XV, 1).

36 Suárez, F., Tratado de las leyes..., vol. II, p. 257 (III, XV, 6); SuÁrez, F., Tratado de las leyes..., vol. I, p. 63 (I, XI, 9).

37 Podemos considerar, por ejemplo, el Fuero de Sahún concedido por Alfonso VII, donde se dice lo siguiente: «Como en todo contrato se confirma con la autoridad del imperio que valgan las condiciones, así también la razón de la Justicia exige que las que se establecen por los reyes y emperadores se confirmen con escrito para que con el transcurso de los tiempos no caigan en el olvido». Consultado en García-Gallo, A., Manual de Historia del Derecho Español, vol. II, [s. ed.], Madrid, 1982, p. 193. 
probablemente tuvo un alcance reducido, entre otras cosas por cuestiones de accesibilidad. Quizá sea interesante señalar que desde el siglo XIV, la forma de facilitar el conocimiento del derecho era conservar las leyes en un arca en cada lugar. En el reinado de Isabel y Fernando así se ordenó, pero esta práctica no garantizaba el conocimiento por parte de la comunidad ${ }^{38}$.

En cualquier caso, conviene precisar que en el pensamiento de Suárez, la forma escrita queda enmarcada en los ámbitos de la congruencia, mayor utilidad $^{39}$ o conveniencia $^{40}$, y no en la esencia de la ley. El resultado de ello es que cabe la posibilidad de que se promulgue una ley no escrita y que se conserve en la comunidad por medio de la tradición ${ }^{41}$. Es suficiente, por tanto, con que la voz de quien pregona publique la ley de forma suficiente, y que posteriormente perdure en la memoria de las personas ${ }^{42}$. Lo dicho se plantea a propósito de la ley en términos generales. Desde un punto de vista más concreto, dentro del ámbito de la ley canónica, el jesuita precisa que los estatutos de inferiores al Papa deben darse por escrito, para que quede constancia de que proceden del poder legislativo ${ }^{43}$.

La afirmación de que puede existir una ley no escrita contrasta con las circunstancias de ordenamientos jurídicos como el nuestro, aunque lo cierto es que esta percepción se puede observar tiempo antes. Bentham ya fue muy crítico en este sentido. Para él una ley merece tal nombre únicamente cuando está escrita. Entre los problemas que considera en caso contrario encontramos la incertidumbre o las modificaciones desapercibidas ${ }^{44}$. Además, el autor utilitarista entiende que quienes admiran la ley no escrita lo hacen porque se

38 García-Gallo, A., Manual..., vol. I, pp. 296, 297.

39 SuÁrez, F., Tratado de las leyes..., vol. II, pp. 257, 258 (III, XV, 6).

40 Sú́rez, F., Tratado de las leyes..., vol. I, p. 63 (I, XI, 9).

41 Suárez, F., Tratado de las leyes..., vol. II, p. 258 (III, XV, 6).

42 SuÁrez, F., Tratado de las leyes..., vol. I, p. 63 (I, XI, 9).

43 Suárez, F., Tratado de las leyes..., vol. II, p. 429 (IV, XIV, 2). En la Iglesia tenían el poder legislativo las personas con autoridad. Debe señalarse, no obstante, que ni siquiera los concilios tenían autoridad para sancionar las normas, siendo necesario para ello la autoridad papal (exceptuamos de este comentario la teoría conciliarista del siglo XV). Sobre ello GARCíAGaLlo, A., Manual..., vol. I, p. 217. Es posible que Suárez estuviera pensando en la legislación conciliar. Según la fuente recientemente citada de GARCíA-GALLO, Graciano se refiere a estas leyes con la expresión «statuta conciliorum». Por otra parte, en el latín de SuÁRez leemos «statuta». Esta denominación debió ser común en la época. En una obra de entonces leemos «el estatuto que se haze en Concilio general, nacional, o prouincial». Bermudez de PedraçA, F., Arte legal para estvdiar la ivrisprvdencia, Emprenta de Antonia Ramirez, Salamanca, 1612, p. 80. No obstante, el jesuita podría haber tenido en mente los estatutos de otros ámbitos, como por ejemplo los institutos religiosos. El autor considera que la palabra en cuestión es una «ley municipal» de contextos como el señalado. SuÁrez, F., Tratado de las leyes y de Dios legislador, vol. III, Instituto de Estudios Políticos, Madrid, 1968, p. 458 (V, I, 7).

44 Bentham, J., Tratados de legislación civil y penal, Editora Nacional, Madrid, 1981, p. 530, 576. La intención de este autor era enfrentarse a la creación judicial del derecho (DE PÁramo, J. R., o. c., p. 135). En Bentham, J., Tratados de legislación civil y penal..., p. 530, leemos «Solamente la mayor integridad de un tribunal puede estorbar á los jueces el hacer de una ley no escrita un medio continuo de favor y de corrupción». A propósito de ello, puede 
estima una forma de poder, reputación o riqueza; «por la misma razón que los sacerdotes de todas las religiones aman los dogmas y los misterios ${ }^{45}$. Podría entenderse que estas palabras son una crítica al iusnaturalismo, pues Bentham en su discurso se refiere puntualmente al derecho natural. Sin embargo, difícilmente podría verse en tal detalle una objeción a la propuesta de Suárez. Por una parte, porque con mayor razón cabría entender que el autor ilustrado tuvo en mente el iusnaturalismo de Burke, de tipo no racionalista e historicista, al que se enfrentó el positivismo inglés, de carácter progresista y codificador ${ }^{46}$. Por otra parte, porque las palabras de Suárez no parecen ir referidas a la ley natural. Sin embargo, conviene apuntar que el planteamiento de Bentham va más allá de la mera crítica al iusnaturalismo, pues aunque como señalamos, en él se refiere al derecho natural, su exposición parece tener una proyección más general capaz de englobar a todas las leyes no escritas. En este sentido, entendemos que sus palabras sí podrían alcanzar a la propuesta de Suárez.

Conviene, no obstante, apuntar que lo que hace el granadino es acercar una idea que debía gozar de un asentimiento considerable en su época y en la precedente. Así lo prueba su recurso al argumento de autoridad, cuando cita a Nicolás Tudeschis, Felino, Selva, Castro y Torquemada ${ }^{47}$; o el hecho de que después Hobbes dejase también constancia de las leyes no escritas en su Leviatán $^{48}$. Algunas de las fuentes citadas por el jesuita nos invitan además a pensar que podría haber conocido una decisión de la Rota Romana del año 1378 , en la que se reconoció la existencia de la ley no escrita, y que al parecer siguió principalmente lo que había establecido Juan de Andrés sobre la cuestión ${ }^{49}$. En el latín de Suárez leemos «vt est communis sententia iuris interpretum in Rubr.de Constit.ubi precipuè Panormit.\&Felin $[\ldots]{ }^{50}$; un texto

resultar interesante señalar que SuÁREZ reconoce la creación judicial del derecho: SuÁREz, F., Tratado de las leyes..., vol. II, p. 260 (III, XV, 11).

45 Bentham, J., Tratados de legislación civil y penal..., p. 530.

46 De Páramo, J. R., o. c., pp. 127, 128.

47 Según el granadino este último basa su afirmación en San Isidoro. SuÁrEz, F., Tratado de las leyes..., vol. I, p. 63 (I, XI, 9). A propósito de esta cita, puede resultar interesante hacer notar que Suárez se separa del significado etimológico de la palabra ley que, no obstante, cita en algún momento y que según el autor de la patrística procede de 'leer'. Suárez, F., Tratado de las leyes..., vol. I, p. 60 (I, XI, 1). Para una lectura de la fuente original: SAN IsIDORo DE SEvilla, Etimologías, Biblioteca de Autores Cristianos, Madrid, 2004, p. 501. La apreciación, no obstante, está en consonancia con la línea que consideraremos más adelante, con ocasión de la apuesta de Suárez por el significado usual de las palabras.

48 Hobbes, T., о. c., pp. 231, 235. Entendemos que la apreciación de este autor puede considerarse a propósito del tema que tratamos, ya que señala que ley civil es «Aquella serie de reglas que el Estado le ha mandado [a cada súbdito] de palabra, o por escrito», y poco después se refiere a la ley no escrita y formulada «de viva voz» por quien tiene el mando.

49 Sobre ello DolezaleK, G., "Scriptura non est de substantia legis. A propos d'une décision de la Rote Romaine, de l'an 1378 environ", en: Diritto comune e diritti locali nella storia dell'Europa, C. E. Giuffrè, Milano, 1980, p. 55.

50 SuÁrez, F., Tratado de las leyes..., vol. I, p. 63 (I, XI, 9). 
que confirma dos de las fuentes del jesuita ya mencionadas («Panormitani» ${ }^{51}$ remite a Nicolás de Tudeschis, y «Felin» a Felino) y la ubicación de su discurso: «in Rubr.de Constit.» Bajo este rótulo (entendemos «de Constitutionibus»), según nuestra interpretación tanto Tudeschis como Felino tienen en cuenta la cuestión que pretendía dirimirse en la decisión de la Rota: si se aceptaba que pudiera probarse por testimonios la existencia de una ley no escrita ${ }^{52}$.

Cabría, no obstante, preguntarse acerca de qué ejemplos pudo haber tenido en mente el jesuita a la hora de desarrollar su planteamiento sobre las leyes no escritas. La parte final del desarrollo anterior invita a pensar en los estatutos, pues parece que la decisión de la Rota giró en torno a una norma de este tipo ${ }^{53}$. Sin embargo, aun en el caso de que el jesuita hubiese tomado en consideración este detalle, cabría reflexionar acerca de si en su discurso sobre la ley no escrita tuvo en mente los estatutos. A propósito de ello, conviene recordar el parecer de Suárez sobre dichas normas que consideramos anteriormente, y añadir que para el autor los estatutos de inferiores al Papa deben darse por escrito, como así acontece siempre ${ }^{54}$.

Por otra parte, podría pensarse que Suárez estaba pensando en la costumbre. A propósito de ello cabría entender que el autor tenía en mente los ordenamientos no formulados (fueros o costumbres) de la Alta Edad Media y época posterior, donde las formulaciones se combinaban con la pervivencia de los ordenamientos no formulados ${ }^{55}$. Sin embargo, esta hipótesis no es plausible por lo siguiente.

51 Como puede verse en los primeros comentarios que citamos en la nota a pie de página siguiente, en el comienzo de su encabezado leemos «Abbatis Panormitani».

52 Dolezalek, G., o. c., p. 55. En el caso de Tudeschis puede localizarse la idea en Abbatis Panormitani, Commentaria Primae Partis in Primum Decretalium Librum, [s. ed.], Lvgdvni, MDLXXXVI, p. 14 (reverso). En cuanto al desarrollo de Felino (auditor de la Rota, según se constata en la portada de la obra que citamos a continuación), la localización se encuentra en [Sandaeus, F.], Commentariorvm Felini Sandei, Ferrariensis... ad V. libros Decretalium, Pars Prima, Apud Heredes Nicolai Beuilaquae, Avgvstae Tavrinorvm, MDLXXVIII, pp. 8 (verso y reverso). Quisiéramos señalar que en estos textos hemos localizado otros detalles que, según nuestra interpretación, podrían tener relación con la Rota. En el de Tudeschis leemos «Rot.decis.238.alias33» (p. 14, reverso); entendemos que se trata de una decisión de la Rota, aunque la numeración no concuerda con la que estudia Dolezalek (en este caso se trata de la número 246, pero en otras referencias no parece mantenerse dicha numeración. Da cuenta de ello el propio estudio de Dolezalek, G., o. c., p. 61, nota a pie de página número 41). Por otra parte, en el texto que antecede inmediatamente al anterior leemos «Io.And. in reg.nemo potest ad impossibile de re.iur.li.6.in mercu.» (p. 14, reverso). Interpretamos que en este punto se hace referencia a la parte de la obra de Juan de Andrés en la que se trata la cuestión de la ley no escrita: ANDREe, J., Mercuriales questiones sup. regulis iuris, Joannisantonij birrete [...] impensis, Papie, 1491, p. 30 (verso y reverso). Consultado en http://bdh-rd.bne.es/viewer. vm?id=0000188839\&page=1. Fecha de consulta: 7/12/2016. En el texto de Felino entendemos que también se recoge esta cita (p. 8, verso).

53 Existe la presunción de que se trataba de dos eclesiásticos que se disputaban una canonjía. Incluso en la referencia a Nicolás III que aparece en la argumentación leemos que numerosos capítulos catedralicios tienen «statuta et consuetudines scripta et non scripta». DolezaleK, G., o. c., p. 55.

54 SuÁrez, F., Tratado de las leyes..., vol. II, p. 429 (IV, XIV, 2)

55 García-Gallo, A., Manual..., vol. I, pp. 181, 182. 
Es cierto que a propósito del contexto que analizamos, en alguna ocasión se ha relacionado el carácter no escrito de la ley con la costumbre en el pensamiento suareciano $^{56}$. Ciertamente, cuando el autor se ocupa de la costumbre se refiere a su carácter no escrito, pero establece su creación en la práctica ${ }^{57}$, algo que marca diferencias con respecto al desarrollo que aquí nos ocupa, donde entra en juego la promulgación. La diferencia queda además constatada explícitamente por el jesuita, cuando considera la formalidad escrita y no escrita, y a propósito de ello afirma que en ese punto no se está refiriendo a la costumbre ${ }^{58}$.

También podría pensarse que la afirmación de Suárez quizá trajo causa de una revisión histórica del derecho romano, en base a la cual podría haber concluido que en algunas épocas existieron leyes no escritas. El análisis en este sentido puede apoyarse en el hecho de que durante la Edad Moderna fue bastante común la consulta del derecho romano ${ }^{59}$. Es cierto que en este contexto el derecho no escrito remite a la costumbre ${ }^{60}$, pero parece que también al tipo de normas que aquí nos interesan ${ }^{61}$. Tal categoría se percibe además en circunstancias o aspectos de la época citada. Pomponio, por ejemplo, da cuenta de un periodo en el que no había textos jurídicos, considerándose como normas las decisiones reales ${ }^{62}$. Además de lo anterior, pensamos que Suárez podría haber tenido en mente el hecho de que existieran normas pontificias que no circulaban escritas ${ }^{63}$. Esta opción queda confirmada si tenemos en cuenta que el propio autor se refiere explícitamente en su obra a este tipo de normas ${ }^{64}$. Un ejemplo de ellas es la constitución de abdicación del Papa Celestino V, citada en la decisión de la Rota a la que antes hicimos alusión ${ }^{65}$.

56 Recasens Siches, L., o. c., p. 153.

57 SuÁrez, F., Tratado de las leyes y de Dios legislador, vol. IV, Instituto de Estudios Políticos, Madrid, 1968, p. 773 (VII, I, 7). Sobre esta cuestión, aunque no enmarcada en la obra del jesuita, DolezaleK, G., o. c., p. 53.

58 SuÁrez, F., Tratado de las leyes..., vol. II, p. 257 (III, XV, 5).

59 García-Gallo, A., Manual..., vol. I, p. 405.

60 Justiniano, «De la Instituta», en: García del Corral, I. L., Cuerpo del Derecho Civil Romano, Lex Nova, [Valladolid], [2004], p. 7. (I, II, 9).

61 Así, en Dolezalek, G., o. c., p. 58, se hace referencia a las leyes derivadas de la interrogación a las magistraturas, que se realizaban de viva voz. Uno de los apoyos del argumento es Justiniano, o. c., p. 6 (I, II, 4). Sobre ello también la siguiente referencia, que considera la citada al comienzo de esta nota: Petit, C., Discurso sobre el discurso. Oralidad y escritura en la cultura jurídica de la España liberal, Universidad Carlos III de Madrid, [Madrid], 2014, p. 148. Consultado en http://e-archivo.uc3m.es/bitstream/handle/10016/19670/discurso_ petit_hd30_2014.pdf?sequence=3. Fecha de consulta: 9/11/2016.

62 Lazo, P., «La incertidumbre del texto en la experiencia jurídica romana. A propósito de D.1,2,2,1-3», en: Revista Chilena de Derecho, 41, 2014, pp. 1189-1198.

63 Sobre estas manifestaciones Petit, C., o. c., p. 148.

64 SuÁrez, F., Tratado de las leyes y de Dios legislador..., vol. II, p. 429 (IV, XIV, 2).

65 DolezaleK, G., o. c., p. 55. En la argumentación de la decisión localizamos también la cita de los siguientes documentos, en los que se reconoce la ley no escrita: una declaración del Papa Gregorio I sobre un canon del Decreto de Graciano (en la línea de lo que dice el Digesto) y un decretal del Papa Nicolás III (p. 55 de la referencia citada). 


\section{Nivel LÉXICO-SEMÁNTICO}

Además de las consideraciones anteriores, la obra de Suarez recoge también otros aspectos que hoy podríamos calificar de léxico-semánticos, relativos al lenguaje legislativo. En la parte de su obra dedicada a la interpretación, el autor considera que en el lenguaje de las leyes podemos encontrar palabras con significado natural y civil ${ }^{66}$, es decir, palabras que forman parte del lenguaje común y del jurídico. Pérez Luño ha considerado que este discurso anticipa la estructura normativa en el ámbito contemporáneo, dado que en aquella encontramos un supuesto de hecho, donde se describen con lenguaje ordinario las acciones o circunstancias, y la consecuencia jurídica, donde encontramos el lenguaje técnico ${ }^{67}$. Desde una perspectiva más general, cabría señalar que el discurso de Suárez contempla a grandes rasgos la tipología lexicográfica contemporánea, que ve en el lenguaje legislativo léxico común y jurídico. Incluso, como veremos en este apartado, en lo que respecta a la última categoría recoge la posibilidad de que pueda estar formada por palabras usadas exclusivamente en el ámbito jurídico, o bien por terminología procedente del lenguaje común ${ }^{68}$.

Con ocasión del análisis del léxico civil, el autor granadino considera que el significado de las palabras que forman parte de aquel lo tienen por «ampliación, igualación o ficción del derecho». Concretamente, a modo de ejemplo se fija en la palabra «muerte», que en el contexto jurídico no hace referencia a la muerte natural, sino a la civil ${ }^{69}$. Como es sabido, la circunstancia apuntada se da también en nuestros días. En relación a ello se ha dicho que aquella puede suponer un obstáculo para el entendimiento del lenguaje por parte de la ciudadanía, si bien es cierto que existen diferentes técnicas para solucionar el problema. Entre ellas, encontramos la de la definición ${ }^{70}$. Suárez no hace referencia explícita a esta opción, pero entendemos que sí de forma indirecta, tanto en lo dicho anteriormente, como principalmente en el siguiente extracto: «a no ser que [...] otros textos jurídicos fuercen a ampliar o limitar ese significado [...] Así se deduce del Código, en el que la edad perfecta o legítima — así llamada sin más- se dice que significa la edad natural y no la señalada por concesión imperial» ${ }^{71}$.

Los datos que acabamos de exponer pensamos que resultan interesantes, puesto que el texto de Suárez bosqueja la estructura de lo que hoy conocemos como definiciones estipulativas; una tipología ya presente en la Escolástica,

66 Sú́rez, F., Tratado de las leyes y de Dios legislador..., vol. IV, p. 626 (VI, I, 9).

67 Pérez LuÑo, A.-E., «Francisco Suárez...», pp. 16, 17.

${ }_{68}$ En nuestros días tales apreciaciones pueden localizarse, por ejemplo, en PRIETO DE Pedro, J., Lenguas, lenguaje y derecho, Civitas, Madrid, 1991, pp. 164 y ss.

69 SuÁreZ, F., Tratado de las leyes..., vol. IV, p. 626 (VI, I, 9).

70 Sobre ello Zapatero, V., El Arte de Legislar, Thomson-Aranzadi, Pamplona, 2009, pp. 264, 265; Prieto de Pedro, J., o. c., pp. 169, 170.

71 SuÁrez, F., Tratado de las leyes..., vol. IV, pp. 626, 627 (VI, I, 9, 10). 
enmarcada en las denominadas definiciones nominales, que se diferenciaba de otro tipo de definiciones, las reales, con las cuales se pretendía captar la esencia de las $\operatorname{cosas}^{72}$. En nuestros días, el análisis relativo a las definiciones estipulativas recuerda algunos de los detalles recientemente expuestos a propósito del discurso del jesuita. Así, se considera que con la tipología en cuestión se establece «un significado legal partiendo del significado común del término que se define». De este modo se configura el significado, aunque ello no se produce dejando totalmente al margen el sentido usual ${ }^{73}$. En este ámbito quien legisla pretende varios objetivos, entre ellos, el de ampliar o restringir los significados de lo que se define con respecto a su uso común ${ }^{74}$.

El desarrollo del granadino va más allá de la consideración del significado natural y civil de las palabras. En aquel también se trata, incluso con especial énfasis, el significado usual, es decir, el que procede del uso o costumbre. Según su parecer, a la hora de interpretar el significado de las palabras ha de tenerse en cuenta el uso que se hace de ellas, en vez de «la propiedad de los términos» ${ }^{75}$. De este modo, si el uso de una palabra es común en una comunidad en su lenguaje vulgar, dicho significado es más propio que el originario, dado que el uso en cuestión deroga lo que estaba establecido con anterioridad ${ }^{76}$. Con ello el granadino se aleja de la postura que pretende buscar la esencia de las palabras, defendiendo lo que Garzón Valdés ha denominado "tesis de la desmitologización ${ }^{77}$. Este desarrollo se ubica en la parte de la obra de Suárez dedicada a la interpretación. No obstante, pensamos que en su trabajo también puede localizarse algún detalle donde se aprecia la idea en el proceso legislativo. Así, podemos fijarnos en la palabra «queremos», a la que el jesuita se refiere a propósito de la promulgación legislativa. Como sabemos, la manifestación de esta ha de constatar el carácter preceptivo de la ley, y a propósito de ello cabría preguntarse acerca de si la palabra en cuestión pudiera resultar apropiada. La propuesta del granadino es analizar las circunstancias, y además considera que en el ámbito legislativo tiene el sentido de obligar, salvo que por el uso se entendiese otra $\operatorname{cosa}^{78}$.

Teniendo en cuenta lo anterior, puede resultar interesante constatar que en el contexto jurídico de nuestro tiempo se ha venido reiterando una tendencia, que entiende que las palabras reflejan la esencia de las cosas, derivándose de ello la consecuencia de que no puedan cambiarse significados, sino reconocerlos.

72 Salvador Coderch, P., «Definiciones y remisiones», en: Sáinz Moreno, F., da Silva Oснод, J. C. (coords.), La calidad de las leyes, Parlamento Vasco, Vitoria, 1989, pp. 161, 162.

73 Ibid., pp. 162, 163, 166.

$74 \quad$ Ibid., pp. 166, 167.

75 SuÁrez, F., Tratado de las leyes..., vol. IV, p. 626 (VI, I, 9).

76 Ibid., p. 626 (VI, I, 9).

77 GARZón VALDÉS, E., "Las palabras de la ley y su interpretación. Algunas tesis de Francisco Suárez», en: Diánoia, 23/23, 1977, p. 31. Consultado en http://dianoia.filosoficas. unam.mx/files/7813/6995/0239/DIA77_Garzon.pdf. Fecha de consulta: 20/10/2016. Puede verse también Pérez LuÑo, A.-E., «Francisco Suárez...», p. 16.

78 SuÁREz, F., Tratado de las leyes..., vol. II, p. 260 (III, XV, 10). 
Frente a ello encontramos la postura de la filosofía analítica, desde donde se considera que la relación entre las palabras y la realidad se establece por las personas de forma convencional ${ }^{79}$. En atención a lo dicho, cabría entender que el desarrollo de Suárez se encontraría en esta segunda línea, si bien ello no es razón suficiente para ver en el autor un precedente de aquella filosofía (el mero recordatorio de que en ella influyó el Círculo de Viena ${ }^{80}$ entendemos que es un dato representativo).

Para Suárez, por tanto, lo importante es considerar el significado de las palabras teniendo en cuenta el uso que se hace de ellas. Más adelante, en su desarrollo señala que la regla es aplicable «sobre todo a palabras usuales que [...] las leyes o los textos jurídicos toman de la ley común de los hombres», y a continuación se refiere a los términos inventados por el derecho, como por ejemplo «censura», «excomunión», «usucapión» o «prescripción». En estos casos el jesuita considera que su significado ha de ser el que se impuso originariamente ${ }^{81}$. Estas últimas declaraciones quizá pudieran dar lugar a pensar que la «tesis de la desmitologización» no se aplica al tipo de terminología señalada. Si esta interpretación es correcta, la postura de Suárez pudiera considerarse objetable en este punto. A propósito de ello cabría recordar que las instituciones evolucionan y que con ello, probablemente también cambie el significado de la terminología que hace referencia a aquellas. Incluso podrían aparecer nuevas acepciones de las palabras ${ }^{82}$. No obstante, la objeción no tendría lugar si se entiende que del texto del granadino se puede inferir lo siguiente: tanto las palabras comunes como las técnicas son susceptibles de cambios que vienen dados por los usos ${ }^{83}$. Este punto de vista podría apoyarse en el detalle de que como ya se ha visto, para Suárez la regla de recurrir al significado usual de las palabras se aplica "sobre todo» a aquellas que las leyes toman de la ley común de las personas; fórmula que da lugar a interpretar que el ámbito de aplicación del discurso no queda restringido a las palabras citadas. Es decir, la regla en cuestión podría considerarse también a propósito de la última categoría de palabras que nos ha ocupado, aunque de forma menos relevante desde el punto de vista cuantitativo. Sin embargo, esta percepción contrasta con la afirmación de que los términos propios del derecho han de tomarse en su su significado original.

79 Podemos citar, por ejemplo, Zapatero, V., Garrido Gómez, M. ${ }^{a}$ I., Arcos Ramírez, F., El Derecho como proceso normativo. Lecciones de Teoría del Derecho, Servicio de Publicaciones de la Universidad de Alcalá, 2. ${ }^{a}$ edición, Alcalá de Henares, 2010, p. 21; Nino, C., o. c., pp. 11 y ss.

80 Sobre ello puede verse Pérez LuÑo, A.-E., Trayectorias contemporáneas de la Filosofía y la Teoría del Derecho, Tébar, Madrid, 2007, p. 45.

81 SuÁrez, F., Tratado de las leyes..., vol. IV, pp. 626, 627 (VI, I, 10).

82 García-Gallo, A., Manual..., vol. I, pp. 289, 290.

83 Opción que contempla Garzón ValdÉs, E., o. c., pp. 31, 32. Cuando este autor se refiere a las palabras técnicas entendemos que en ellas incluye las que nos ocupan en este punto, pues pone como ejemplos de expresiones técnicas «prescripción» o «usucapión». 


\section{LA CLARIDAD DEL LENGUAJE COMO ASPECTO CONVENIENTE Y ESENCIAL}

Cuando Suárez analiza la promulgación que ha de considerarse suficiente para poder hablar de ley, se refiere a la ley «clara y manifiesta» que aparece en la obra de San Isidoro. Para el jesuita esta condición puede considerarse referida a las palabras de la ley, o bien al hecho de que se haga pública para que su audiencia la pueda leer y oír. Esta segunda interpretación remite a un aspecto esencial de la ley ${ }^{84}$. No obstante, para los intereses que nos ocupan en este espacio, resulta especialmente relevante la aplicación de la expresión con la que comenzamos al primer ámbito señalado. Más concretamente, el autor dice que la condición de ley clara y manifiesta puede referirse a las palabras de aquella, es decir, a su claridad para que «no ofrezcan ocasión de error o tergiversación ni de opiniones e interpretaciones, de las cuales suelen nacer engaños y contiendas» ${ }^{85}$.

Al contrario que en el caso de la promulgación, la claridad de las palabras de la ley no forma parte de su esencia. Ello, no obstante, no quiere decir que no tenga importancia para Suárez. La tiene, pero desde el punto de vista de la perfección legislativa ${ }^{86}$, así como desde la conveniencia. En este sentido, la recomendación es utilizar palabras «sencillas, breves y claras», pues si son muy prolijas darán más lugar a la duda y a la ambigüedad ${ }^{87}$. En definitiva, lo que está en juego con estas cuestiones es la obtención de la mayor seguridad jurídica posible ${ }^{88}$.

Las recomendaciones del autor parecen enlazar con la tradición rescatada en la Baja Edad Media, de una técnica de redacción depurada, que contrasta con las incorrecciones gramaticales y podredumbre lingüística que se observan en la Alta Edad Media ${ }^{89}$. La preocupación por estas cuestiones siguió estando presente en la época posterior a Suárez ${ }^{90}$ y llega hasta nuestro

84 SuÁrez, F., Tratado de las leyes..., vol. I, p. 60 (I, XI, 1)

85 Ibíd., p. 60 (I, XI, 1).

86 Ibíd., p. 60 (I, XI, 1).

87 SuÁrez, F., Tratado de las leyes..., vol. II, p. 256 (III, XV, 1). En su desarrollo posterior el autor considera el ejemplo de la palabra «queremos», que ya conocemos. Suárez entiende que se trata de una palabra ambigua, puesto que puede hacer referencia a la voluntad de obligar, o bien a la expresión de un deseo o inclinación. Suárez, F., Tratado de las leyes..., vol. II, p. 260 (III, XV, 10). Como ya señalamos, el jesuita resuelve el problema recurriendo al análisis de las circunstancias, una fórmula que guarda cierto parecido con la remisión al contexto que se considera en nuestros días, a propósito de la ambigüedad semántica (sobre la solución Zapatero, V., El Arte de Legislar, p. 261), que es la que tiene lugar en el caso expuesto.

88 Pérez Luño, A.-E., «Francisco Suárez...», p. 17. Comentando la cuestión del lenguaje normativo en Suárez, este autor señala lo siguiente: «...deberá evitarse, como factores que dificultan el conocimiento de la ley y entrañan un margen de inseguridad jurídica [...] [la] vaguedad del lenguaje normativo...».

89 Sobre estos datos históricos García-Gallo, A., Manual..., vol. I, p. 291.

90 Podemos, por ejemplo, citar a HobBes, T., о. c., p. 232, donde leemos que «los mandatos deben darse con signos suficientemente claros, ya que, de otro modo, un hombre no sabría cómo obedecerlos». 
tiempo ${ }^{91}$; si bien es cierto que las aspiraciones más ambiciosas se manifestaron algunos siglos antes, concretamente en el pensamiento ilustrado. Bentham, por ejemplo, consideraba que a mayor volumen «mayor, más perfecto y exquisito es el grado de ambigüedad y oscuridad $»^{92}$. En estas palabras se encuentra a nuestro juicio la recomendación de brevedad lingüística presente en el pensamiento del jesuita. Su propuesta, no obstante, se aleja de los ideales ilustrados desde numerosas perspectivas. Así, podemos señalar que, como veremos después, para Suárez no es posible una claridad absoluta ${ }^{93}$ y que, por ende, su punto de vista también cuestiona el carácter no necesario de la interpretación por terceras personas, que sí se pretendía con el paradigma ilustrado $^{94}$. El planteamiento del jesuita es más modesto en este punto; con ello se aleja de los ideales recientemente expuestos y se muestra más afín a los planteamientos que encontramos en la literatura jurídica contemporánea.

Para Suárez el camino hacia aquella conveniencia que sugiere con respecto a la sencillez, brevedad y claridad, nunca logrará un resultado capaz de eliminar todas las dudas de interpretación que pudieran suscitar las leyes; «apenas es posible humanamente emplear tal diligencia», dice el jesuita ${ }^{95}$. Su discurso en este punto resulta sumamente interesante por lo que tiene de vigente. Analizado desde nuestro tiempo, casi es ineludible citar a Hart. Garzón Valdés ya apuntó que la referencia a la «duda» en Suárez remite a aquellos casos en los que Hart considera una zona de penumbra ${ }^{96}$. No obstante, el ejercicio de comparación puede ser más rico. Merece la pena recordar también en este punto que para el jesuita, las dudas aparecerán frecuentemente en la aplicación de la ley que hable de forma breve y general ${ }^{97}$. Pues bien, en el pensamiento hartiano encontramos este detalle, además de la referencia a la «condición humana» que, como vimos anteriormente, también forma parte del discurso suareciano. Concretamente, Hart considera que cuando se pretenda regular sin ambigüedad alguna conducta con criterios generales, encontraremos dos obstáculos: por una parte, la «relativa ignorancia de los hechos», y por otra la

91 Sirva como ejemplo citar las siguientes referencias: Zapatero, V., El Arte de Legislar, pp. 259 y ss.; Prieto de Pedro, J., o. c., pp. 179 y ss.

92 Bentham, J., Nomografía o el arte de redactar leyes, Centro de Estudios Políticos y Constitucionales, Madrid, 2004, p. 34.

93 Cabría señalar, no obstante, que Bentham parece considerar uno de los argumentos de Suárez en los siguientes términos, si bien su discurso no recoge los problemas que sí aparecen en el del jesuita: no es posible prever todos los casos que pudieran suceder; pero aunque la previsión no pueda ser individual, sí que es posible establecerla en especie. Bentham, J., Tratados de legislación civil y penal..., p. 529.

94 Sobre el pensamiento ilustrado en esta cuestión ZAPATERo, V., «El arte ilustrado de legislar», en: Bentham, J., Nomografía o el arte de redactar leyes, Centro de Estudios Políticos y Constitucionales, Madrid, 2004, pp. LXI y ss.; Arcos Ramírez, F., La Seguridad Jurídica: Una Teoría Formal, Dykinson, Madrid, 2000, pp. 256-259.

95 SuÁrez, F., Tratado de las leyes..., vol. I, p. 60 (I, XI, 1).

96 GARZÓN VALDÉs, E., o. c., p. 33.

97 SuÁrez, F., Tratado de las leyes..., vol. IV, p. 625 (VI, I, 5). 
«indeterminación de propósitos». Humanamente, considera Hart, es imposible conocer todas las circunstancias que puedan acontecer en el futuro ${ }^{98}$. En este último argumento se encuentra a nuestro juicio la razón por la cuál Suárez enmarca la claridad normativa dentro del ámbito de la conveniencia. Lo dicho, no obstante, no debiera invitar a ver en el autor granadino un precursor del positivismo de estilo hartiano, ni tampoco, de nuevo, y desde una perspectiva más general, de la filosofía analítica, que otorgó en el siglo pasado un papel principal al análisis del lenguaje ${ }^{99}$. Probablemente sea más apropiado, como se ha dicho, hablar de Suárez como precursor del pensamiento jurídico de la época contemporánea ${ }^{100}$; o bien quizá como antecedente de numerosas ideas y planteamientos que hoy percibimos en dicho contexto. Una prueba de ello es que las consideraciones del jesuita también encuentran reflejo en textos contemporáneos, que han sido objeto de crítica por parte de Hart, como por ejemplo el dedicado a la moral interna del derecho de Fuller, para quien en ocasiones es necesario recurrir a términos vagos ${ }^{101}$.

Como hemos señalado, para Suárez la claridad de las palabras de la ley no tiene carácter esencial, es decir, una ley con un lenguaje oscuro, que dé lugar a diferentes interpretaciones, no sería impedimento para reconocer que nos encontramos ante una ley. Cabría, no obstante, preguntarse hasta qué punto defiende el jesuita este discurso o, en otras palabras, si considera que nos encontramos ante una ley en el caso de que su lenguaje sea totalmente ininteligible. Una primera aproximación a esta cuestión podría ser la siguiente. Como vimos anteriormente, para el autor la ley es un precepto, es decir, obliga. Sin embargo, para que ello tenga lugar debe promulgarse y además - cabría añadir - se debe poder entender. Este argumento pensamos que se encuentra presente en la obra del autor ${ }^{102}$ que venimos estudiando, aunque no exclusivamente ${ }^{103}$. La interpretación entendemos que también puede apreciarse

98 Hart, H. L. A., El Concepto de Derecho, Abeledo-Perrot, Buenos Aires, 2004, p. 160. Sobre estas cuestiones es interesante la consulta de Zapatero, V., El Arte de Legislar, pp. 262 y ss.

99 Sobre la filosofía analítica puede verse Pérez LuÑo, A.-E., Trayectorias contemporáneas..., pp. 45-49.

100 Pérez Luño, A.-E., «Francisco Suárez...», p. 32.

101 Fuller, L. L., La moral del derecho, Trillas, México, 1964, p. 77.

102 Podríamos considerar las siguientes palabras de Justiniano, que SuÁrez propone a propósito de la necesidad de promulgación de la ley a la comunidad: «Las sacratísimas leyes deben todos entenderlas, a fin de que todos, entendiendo bien claramente lo que prescriben, se aparten de lo prohibido y hagan lo mandado». SuÁrez, F., Tratado de las leyes..., vol. I, p. 61 (I, XI, 3).

${ }_{103}$ La conclusión pensamos que probablemente podría extraerse de SuÁrez, F., Disputaciones metafísicas, vol. III, Gredos, Madrid, 1961 p. 394 (XIX, VI, 8). En esta obra el autor considera que el entendimiento «no puede realizar un acto sino por modo de aprehensión o de juicio»; de otro modo no puede entenderse, como tampoco «el imperio sobre otros si no es por modo de locución que intime lo que deba hacerse». Esta cuestión se considera, junto con otras más relativas a las palabras (externas e internas), en LEcón, M., o. c., pp. 126,130 y ss. 
en varios estudios ${ }^{104}$. Si aceptamos todo ello, podríamos argumentar a sensu contrario que si el texto de la ley no es entendible no puede obligar y, por tanto, no estamos ante una ley.

Suárez confirma el resultado expuesto en la parte de su obra que dedica a la interpretación de la ley humana. En este lugar el jesuita vuelve a la cuestión de las palabras ambiguas. Con vistas a dar una solución al problema que suscitan se refiere a la interpretación, pero además de ello plantea un supuesto en el que las palabras tuviesen tal ambigüedad, que no pudiera determinarse su «sentido preciso». En tal caso, según el autor no estaríamos ante una ley, pues «no sólo no sería clara pero ni siquiera daría a entender suficientemente la mente del legislador ${ }^{105}$. Es decir, la oscuridad que está contemplando Suárez y que impide hablar de ley es tal, que no se podría superar ni recurriendo a la interpretación.

De nuevo, en esta ocasión, nos encontramos con un discurso que nos invita a volver la mirada a la literatura jurídica contemporánea. A propósito de ello, puede resultar interesante la lectura de un estudio de Westerman, donde se afirma que los requisitos para la validez de la ley que considera Suárez se parecen mucho a los que presenta Fuller ${ }^{106}$. Como es sabido, en el relato de este último sobre el gobernante ficticio Rex, un fracaso total en los aspectos formales que considera — entre ellos la claridad- impide que pueda hablarse de derecho ${ }^{107}$. Cabría precisar, no obstante, que este resultado no es genuino del autor citado, pues se comparte por el positivismo ${ }^{108}$. Sin embargo, conviene recordar que entre ambas posturas existe una diferencia insalvable, de la que dejaremos constancia en el siguiente apartado.

\section{JUSTICIA Y CLARIDAD LINGÜÍSTICA}

En este espacio nos proponemos analizar si para Suárez la claridad del lenguaje legislativo forma parte de la justicia. En su obra establece que la ley

104 Así, PÉREZ LuÑo señala que para SuÁREZ el conocimiento legislativo depende de la claridad del lenguaje. Pérez LuÑo, A.-E., «Francisco Suárez...», p. 17 (conviene, no obstante, señalar que este autor considera la cuestión a propósito de las expresiones ambiguas o que susciten confusión). Podemos citar también a Lecón, que señala que para que la ley sea conocida debe exteriorizarse, pues de otro modo no se podría solicitar su obediencia. Así, en la promulgación se ha de formular la ley en "palabras sensibles». Lecón, M., o. c., pp. 136-138. Pensamos que la idea también se encuentra en Macía Manso, R., o. c., p. 139, cuando dice «La obligación [...] exige conocimiento racional del acto en sí mismo, para poder ejecutarlo racionalmente...».

105 SuÁrez, F., Tratado de las leyes..., vol. IV, p. 627 (VI, I, 11).

106 Westerman, P. C., Suárez and the formality of law, p. 10. Consultado en http://www. rug.nl/staff/p.c.westerman/suarez.doc. Fecha de consulta: 19/10/2016. La autora, no obstante, no se refiere a la claridad en SuÁrEz de forma específica.

107 Fuller, L. L., o. c., p. 49. Cabría precisar que las palabras de este autor podrían interpretarse como ausencia de ordenamiento jurídico o de ley. En el caso de SuÁrez nos encontramos ante el último supuesto.

108 Escudero Alday, R., Positivismo y moral interna del derecho, Centro de Estudios Políticos y Constitucionales, Madrid, 2000, p. 349. 
debe ser justa en dos sentidos, desde la perspectiva material y la formal. A propósito de este segundo ámbito, que es el que nos interesa principalmente, considera que la ley ha de darse justamente - aspecto necesario-, es decir, «que observe una forma justa y razonable» ${ }^{109}$. Tal planteamiento se confirma si tenemos en cuenta que a la hora de analizar la necesidad de la justicia para hablar de ley válida, Suárez señala que en dicho sentido se comprende el texto de San Isidoro que habla de ley honesta y justa, haciendo referencia esta última característica a la forma de la ley, que ha de darse justamente ${ }^{110}$.

En vista de lo anterior cabría reflexionar acerca de si la claridad del lenguaje, que hemos considerado en el apartado anterior, pudiera enmarcarse en el planteamiento recientemente expuesto. Entendemos que la respuesta ha de ser afirmativa, pues se trata de un aspecto de la forma de la ley que como hemos visto, para el jesuita debe darse justamente. Quizá pudiera considerarse que las palabras del autor en este tema van dirigidas a la promulgación, pero incluso desde esta perspectiva cabría entender que la cuestión que nos ocupa forma parte de su discurso, siquiera de forma mediata. Como ya se dijo, con la promulgación se da a conocer la ley a la comunidad, y ello conlleva que se pueda entender. Si se acepta tal planteamiento, con él podría considerarse que la claridad del lenguaje legislativo forma parte de los aspectos formales de la ley, y que por tanto, debe verse en aquella una dosis de justicia. No obstante, si esta conclusión es correcta podría ponerse en cuestión con las reflexiones que presentamos en las siguientes líneas.

Como adelantamos en la introducción, en otros trabajos se ha tratado la cuestión que ahora nos ocupa, con ocasión del análisis del pensamiento de Fuller. En ellos se señala que hay razón para sustentar la tesis positivista que ve en los aspectos formales simples recursos de carácter técnico, sin dosis moral alguna ${ }^{111}$. Efectivamente, per se una ley con un lenguaje claro no garantiza su justicia, ni tampoco parece que podamos decir que un lenguaje claro es moral por el mero hecho de que haga posible que se pueda conocer el contenido de la ley. Podría apuntarse, no obstante, que el resultado anterior no se cumple cuando las leyes aparecen en un contexto jurídico en el que se reconocen determinados derechos y libertades, pues en este caso el lenguaje hace posible el conocimiento de estos contenidos ${ }^{112}$. Sin embargo, a nuestro modo de ver es cuestionable que este último planteamiento pueda extrapolarse al discurso de Suárez. En él es evidente que la ley se enmarca dentro del ámbito de la justicia

\footnotetext{
109 SuÁrez, F., Tratado de las leyes..., vol. I, p. 51 (I, IX, 10 bis).

110 Ibid., p. 52 (I, IX, 13).

111 En este punto reside la diferencia a la que nos referíamos al final del apartado anterior. Sobre ello Escudero Alday, R., o. c., p. 349; Westerman, P. C., o. c., p. 10. La cuestión se trata, aunque a propósito de la promulgación normativa, en Centenera Sánchez-Seco, F. «La promulgación de las normas en el pensamiento de Lon L. Fuller: una lectura a propósito del ordenamiento jurídico actual», en: Dereito: revista xurídica da Universidade de Santiago de Compostela, 25, 1, p. 85, 86.

112 Centenera Sánchez-Seco, F., «Buscando el valor de la claridad...», pp. 63 y ss.
} 
material, como ya vimos, pero al menos de manera explícita no se establece que la justicia en la forma de la ley tenga su razón de ser en la función que cumple con respecto al conocimiento de los contenidos de la justicia material. En todo caso, y aun cuando se considerarse que es posible ver el planteamiento expuesto en la obra del jesuita, convendría señalar que su propuesta no podría extrapolarse al discurso jurídico de nuestro tiempo. Su defensa de un iusnaturalismo católico ${ }^{113}$ que fundamenta y vertebra la obra que estudiamos, así lo demuestra. Únicamente secularizando ${ }^{114}$ las ideas del autor podría ser viable la propuesta en cuestión.

\section{Conclusiones}

El análisis del lenguaje de la ley humana en el pensamiento de Francisco Suárez nos presenta a un autor que escribe en la Edad Moderna y que, por tanto, tiene en cuenta los pormenores jurídicos del contexto en el que vivió. El mérito de sus ideas desde esta perspectiva no ofrece lugar a dudas. A propósito de ello, conviene recordar que varios de los principios jurídicos que desarrolla en su obra, aunque ya se apuntan en épocas anteriores y hoy los podamos considerar suficientemente asentados, entonces se estaban desarrollando plenamente con la escolástica moderna ${ }^{115}$. Es cierto que en determinados casos, alguna de sus propuestas contrasta con realidades jurídicas como la nuestra. Quizá el ejemplo más significativo sea el de las leyes no escritas. Sin embargo, el planteamiento del jesuita refleja las circunstancias e intelectualidad de su época.

Además de lo anterior, debe destacarse que en su obra Suárez considera con lucidez determinados aspectos que han sido objeto de atención en el ámbito jurídico en contextos posteriores, y que hoy siguen siendo actuales, bien en la realidad jurídica, bien en el ámbito intelectual. Hablamos de la función prescriptiva del lenguaje legislativo, de su perspectiva léxico-semántica, o de la relevancia de la claridad del lenguaje legislativo desde los puntos de vista de la

113 La crítica se considera, aunque a propósito de la labor de interpretación normativa, en Chiassoni, P., «Entre formalismo y theological reading: Garzón Valdés, Francisco Suárez y la interpretación de la ley», en: Doxa, Cuadernos de Filosofía del Derecho, 30, 2007, p. 87. Sobre esta cuestión, quizá pueda interesar el estudio de Rommen, donde se analiza la justificación del poder estatal que tiene su origen en Dios. En este contexto el autor citado señala lo siguiente: «Donde más claramente se manifiesta esta procedencia es en las facultades del poder del Estado para castigar con la muerte ciertos delitos, pues esto, como dice SUÁREz, sería "imposible sine nutu divino, puesto que Dios es el único señor de la vida" ». Rommen, H., La teoría del Estado y de la comunidad internacional en Francisco Suarez, Instituto Francisco de Vitoria, Madrid, 1951, pp. 266-268.

114 Sobre esta percepción, desde un punto de vista general, Decock, W., «From Law to Paradise: Confessional Catholicism and Legal Scholarship», en: Rechts geschichte, 18, 2011, p. 23. Consultado en https://irias.kuleuven.be/bitstream/123456789/305600/1/From_Law_to_ Paradise_Rg18(2011)-decock.pdf. Fecha de consulta: 24/10/2016.

115 La reflexión en un sentido general se encuentra en Dесоск, W., о. c., p. 23. 
conveniencia, la esencia de la ley y la justicia. Probablemente deba entenderse que el carácter actual que pudiera atribuirse a las ideas de Suárez en nuestro tiempo, deriva del hecho de que su interés — siquiera con carácter puntualpor el lenguaje de las leyes, se ha venido compartiendo tradicionalmente en el mundo del derecho ${ }^{116}$. Sin embargo, ello no debería empañar la relevancia de sus aportaciones que incluso en ocasiones, se acercan más a la situación actual que algunas desarrolladas en los siglos posteriores a su época.

No obstante, lo anterior no debería dar lugar a presentar al autor como precursor de escuelas o posturas contemporáneas, aunque es cierto que esta reflexión no impide ver en su obra un antecedente de numerosas ideas que hoy siguen vigentes en el pensamiento jurídico. Por lo demás, si concebimos la propuesta del jesuita desde una perspectiva más general, no únicamente comprensiva de los aspectos formales sino también de los materiales, debemos señalar que entre aquella y el momento actual existen diferencias, que traen causa de la función fundamental y vertebradora que tiene la religión en la obra del autor.

\section{BiBLIOGRAFÍA}

Abbatis Panormitani, Commentaria Primae Partis in Primum Decretalium Librum, [s. ed.], Lvgdvni, MDLXXXVI.

ANDREe, J., Mercuriales questiones sup. regulis iuris, Joannisantonij birrete...impensis, Papie, 1491. Consultado en http://bdh-rd.bne.es/viewer.vm?id=0000188839\&page $=1$. Fecha de consulta: 7/12/2016.

Amezúa Amezúa, L. C., «Efectos de la Ley y Permisos: el legado de un clásico del Siglo de Oro (Textos para el IV Centenario de Francisco Suárez)», en: I Congreso de Filosofía del Derecho para el Mundo Latino, 26-28 de mayo de 2016. Consultado en http://iusfilosofiamundolatino.ua.es/download/Luis\%20Carlos\%20Amezu \%CC\%81 a\%20-\%20 Espan\%CC\%83a.pdf. Fecha de consulta: 23/10/2016.

Ansuátegui, F. J., «El derecho como norma», en: Peces-Barba, G., Fernández, E., De Asís, R., Curso de Teoría del Derecho, Marcial Pons, segunda edición, Madrid, 2000.

Arcos Ramírez, F., La Seguridad Jurídica: Una Teoría Formal, Dykinson, Madrid, 2000.

Bentham, J., Nomografía o el arte de redactar leyes, Centro de Estudios Políticos y Constitucionales, Madrid, 2004.

Bentham, J., Tratados de legislación civil y penal, Editora Nacional, Madrid, 1981.

Bermudez de Pedraça, F., Arte legal para estvdiar la ivrisprvdencia, Emprenta de Antonia Ramirez, Salamanca, 1612.

Centenera SÁnchez-Seco, F., «Buscando el valor de la claridad de las normas: Algunas reflexiones desde el pensamiento de Lon L. Fuller», en: Bajo Palabra. Revista de Filosofía, 10, 2015, pp. 61-70.

Centenera Sánchez-Seco, F., «La claridad legislativa en el pensamiento de Lon L. Fuller: Un análisis desde la teoría de la legislación», en: Anales de Derecho, 1, 2015, pp. 1-27.

116 En nuestro contexto puede observarse un interés creciente en las décadas más recientes, aunque no comparable al del ámbito anglosajón. 
Centenera Sánchez-Seco, F. «La promulgación de las normas en el pensamiento de Lon L. Fuller: una lectura a propósito del ordenamiento jurídico actual», en: Dereito: revista xurídica da Universidade de Santiago de Compostela, 25, 1, pp. 73-99.

Chiassoni, P., «Entre formalismo y theological reading: Garzón Valdés, Francisco Suárez y la interpretación de la ley», en: Doxa, Cuadernos de Filosofía del Derecho, 30, 2007, pp. 79-87.

De Páramo, J. R., H. L. A. Hart y la teoría analítica del derecho, Centro de Estudios Constitucionales, Madrid, 1984.

Deсоск, W., "From Law to Paradise: Confessional Catholicism and Legal Scholarship», en: Rechts geschichte, 18, 2011, pp. 12-34. Consultado en https://irias.kuleuven.be/ bitstream/123456789/305600/1/From_Law_to_Paradise_Rg18(2011)-decock.pdf. Fecha de consulta: 24/10/2016.

DolezaleK, G., «Scriptura non est de substantia legis. A propos d'une décision de la Rote Romaine, de l'an 1378 environ», en: Diritto comune e diritti locali nella storia dell'Europa, C. E. Giuffrè, Milano, 1980.

Escudero Alday, R., Positivismo y moral interna del derecho, Centro de Estudios Políticos y Constitucionales, Madrid, 2000.

FAssò, G., Historia de la Filosofía del Derecho, vol. 2. La Edad Moderna, Ediciones Pirámide, Madrid, 1979.

Fuller, L. L., La moral del derecho, Trillas, México, 1964.

García-Gallo, A., Manual de Historia del Derecho Español, vol. I, [s. ed.], Madrid, 1982.

García-Gallo, A., Manual de Historia del Derecho Español, vol. II, [s. ed.], Madrid, 1982.

GARZÓN VALDÉs, E., "Las palabras de la ley y su interpretación. Algunas tesis de Francisco Suárez», en: Diánoia, 23/23, 1977, pp. 30-41. Consultado en http://dianoia.filosoficas. unam.mx/files/7813/6995/0239/DIA77_Garzon.pdf. Fecha de consulta: 20/10/2016.

Hart, H. L. A., El Concepto de Derecho, Abeledo-Perrot, Buenos Aires, 2004.

HobBes, T., Leviatán o la materia, forma y poder de un Estado eclesiástico y civil, Alianza Editorial, primera reimpresión, Madrid, 2001.

ItURRAlde SEsma, V., «Consideración crítica del principio de permisión según el cual "lo no prohibido está permitido"», en: Anuario de Filosofía del Derecho, 15, 1998, pp. 187-217.

Justiniano, «De la Instituta», en: García del Corral, I. L., Cuerpo del Derecho Civil Romano, Lex Nova, [Valladolid], [2004].

LAzo, P., «La incertidumbre del texto en la experiencia jurídica romana. A propósito de D.1,2,2,1-3», en: Revista Chilena de Derecho, 41, 2014, pp. 1189-1198.

Lecón, M., Acción, praxis y ley. Estudio metafísico y psicológico de la acción legislativa en Francisco Suárez, EUNSA, Navarra, 2014.

Macía Manso, R., Juridicidad y moralidad en Suárez, Publicaciones del Instituto de Estudios Jurídicos, Oviedo, 1967.

Nino, C., Introducción al análisis del Derecho, Ariel, 11ª edición, Barcelona, 2003.

PÉrez LuÑo, A.-E., "Francisco Suárez y la Filosofía del Derecho actual», en: I Congreso de Filosofía del Derecho para el Mundo Latino, 26-28 de mayo de 2016. Consultado en http://iusfilosofiamundolatino.ua.es/download/ Ponencia\%20Pe\%CC\%81rez\%20 Lun\%CC\% 83o.pdf. Fecha de consulta: 23/10/2016.

Pérez Luño, A.-E., Trayectorias contemporáneas de la Filosofía y la Teoría del Derecho, Tébar, Madrid, 2007.

Petit, C., Discurso sobre el discurso. Oralidad y escritura en la cultura jurídica de la España liberal, Universidad Carlos III de Madrid, [Madrid], 2014. Consultado en 
http://e-archivo.uc3m.es/bitstream/handle/10016/19670/discurso_petit_hd30_2014. pdf? sequence=3. Fecha de consulta: 9/11/2016.

Prematica de tratamientos, y cortesias, y se acrecientan las penas contra los transgresores de lo en ella contenido, Iuan de la Cuesta, Madrid, 1611. Consultado en http://alfama.sim.ucm.es/dioscorides/consulta_libro.asp?ref=b2521844x\&idioma=0. Fecha de consulta: 10/11/2016.

Prematica, y nveva orden, cerca de los vestidos, y trages, assi de hombres, como de mujeres, y de otras cosas, que se mandan guardar, Iuan de la Cuesta, Madrid, 1611. Consultado en http://alfama.sim.ucm.es/dioscorides/consulta_libro.asp?ref=b25218347\&idioma=0. Fecha de consulta: 10/11/2016.

Prieto de Pedro, J., Lenguas, lenguaje y derecho, Civitas, Madrid, 1991.

Recasens Siches, L., La Filosofía del Derecho de Francisco Suárez. Con un estudio previo sobre sus antecedentes en la patrística y en la escolástica, Librería General de Victoriano Suárez, Madrid, 1927.

Rommen, H., La teoría del Estado y de la comunidad internacional en Francisco Suarez, Instituto Francisco de Vitoria, Madrid, 1951.

Salvador Coderch, P., «Definiciones y remisiones», en: Sáinz Moreno, F., da Silva Ochoa, J. C. (coords.), La calidad de las leyes, Parlamento Vasco, Vitoria, 1989.

San Isidoro de Sevilla, Etimologías, Biblioteca de Autores Cristianos, Madrid, 2004.

[Sandaeus, F.], Commentariorvm Felini Sandei, Ferrariensis... ad V. Libros Decretalium, Pars Prima, Apud Heredes Nicolai Beuilaquae, Avgvstae Tavrinorvm, MDLXXVIII.

SuÁrez, F., Disputaciones metafísicas, vol. III, Gredos, Madrid, 1961.

Suárez, F., Tratado de las leyes y de Dios legislador, vol. I, Instituto de Estudios Políticos, Madrid, 1967.

Suárez, F., Tratado de las leyes y de Dios legislador, vol. II, Instituto de Estudios Políticos, Madrid, 1967.

Suárez, F., Tratado de las leyes y de Dios legislador, vol. III, Instituto de Estudios Políticos, Madrid, 1968.

Suárez, F., Tratado de las leyes y de Dios legislador, vol. IV, Instituto de Estudios Políticos, Madrid, 1968.

Truyol y Serra, A., Historia de la Filosofía del Derecho y del Estado, vol. 2. Del Renacimiento a Kant, Alianza Editorial, 2. ${ }^{a}$ edición, Madrid, 1982.

Viver Pi-Sunyer, C., «Sanción, promulgación y orden de publicación», en: GRETEL, Curso de técnica legislativa, Centro de Estudios Constitucionales, Madrid, 1989.

Von Wright, G. H., Norma y Acción. Una investigación lógica, Editorial Tecnos, reimpresión, Madrid, 1979.

Westerman, P. C., Suárez and the formality of law. Consultado en http://www.rug.nl/staff/ p.c.westerman/suarez.doc. Fecha de consulta: 19/10/2016.

Zapatero, V., El Arte de Legislar, Thomson-Aranzadi, Pamplona, 2009.

Zapatero, V., «El arte ilustrado de legislar», en: Bentham, J., Nomografía o el arte de redactar leyes, Centro de Estudios Políticos y Constitucionales, Madrid, 2004.

Zapatero, V., Garrido Gómez, M. ${ }^{a}$ I., Arcos Ramírez, F., El Derecho como proceso normativo. Lecciones de Teoría del Derecho, Servicio de Publicaciones de la Universidad de Alcalá, 2. ${ }^{a}$ edición, Alcalá de Henares, 2010.

Universidad de Alcalá

Fernando Centenera Sánchez-Seco

Facultad de Derecho.

fernando.centenera@uah.es

[Artículo aprobado para publicación en enero de 2018] 